\title{
Kinetic Analysis of the Thermal Processing of Silica
}

\section{and Organosilica}

Emiel J. Kappert, Henny J.M. Bouwmeester, Nieck E. Benes*, Arian Nijmeijer

Inorganic Membranes, Faculty of Science and Technology, MESA+ Institute for

Nanotechnology, University of Twente, P.O. Box 217, 7500 AE Enschede, The Netherlands

\begin{abstract}
The incorporation of an organic group into sol-gel derived silica causes significant changes in the structure and properties of these materials. Therefore, the thermal treatment of organosilica materials may require a different approach. In the present paper, kinetic parameters (activation energy, pre-exponential constant and reaction models) have been determined from mass loss data for the dehydration, dehydroxylation and decomposition reactions that take place upon heating silica and organosilica. Parameters were obtained by employing model-free isoconversional methods to data obtained under multiple heating rates, as well as multivariate analysis of the kinetics using a multistep reaction model with distributed activation energy. For silica, it can be concluded that the reaction atmosphere (i.e., inert or thermo-oxidative) has no influence on the reaction rate of the dehydration and dehydroxylation reactions that are responsible for the densification of the material. Under inert atmosphere, full dehydration can be reached without affecting the organic moiety. Achieving complete dehydroxylation of the organosilica is
\end{abstract}


practically impossible, as decomposition does manifest itself under commonly employed calcination temperatures. This indicates that prudence is required in designing a heat-treatment program for these hybrid materials. To aid in optimizing the thermal treatment, a predictive model was developed, which can be used to forecast the extent of dehydration, dehydroxylation, and decomposition reactions under a multitude of temperature programs.

Keywords: Isoconversional analysis, multivariate analysis of kinetics, hybrid organic-inorganic silica, quantitative kinetic predictions, BTESE 


\section{Introduction}

Organosilica layers are used in a multitude of applications, including membranes ${ }^{1-3}$, low- $\kappa$ dielectrics ${ }^{4,5}$, and optical coatings ${ }^{6,7}$. The properties of these layers can be tailored by a thermal treatment, in which temperature and duration can be changed to obtain the desired properties. Densification of pure silica is classically achieved by using high temperatures $\left(>300{ }^{\circ} \mathrm{C}\right)$ and long treatment times $(>1 \mathrm{hr})$. However, lower treatment temperatures and shorter treatment times are desired to prevent decomposition of the organic moiety in organosilicas ${ }^{8,9}$, to decrease energy use during calcination, or to allow for application of the layer on a supporting substrate with a limited thermal stability ${ }^{10-13}$. Researchers have investigated several strategies to limit the treatment temperature or duration for hybrid and inorganic systems: a long-term treatment at low temperatures ${ }^{14}$, flash heating at high temperatures ${ }^{15-19}$, or a treatment with acids that renders thermal treatment unnecessary ${ }^{2}$.

To obtain a material with a targeted microstructure, one is preferably able to predict and steer the thermal processing. Detailed information on the kinetics of the thermally-activated processes that occur during the calcination of organosilica is required to predict the influence of the thermal treatment. This kinetic data is commonly displayed in the form of the kinetic triplet: the activation energy, the pre-exponential constant, and the reaction model. In the case of a hybrid material such as organosilica, a number of reactions can occur during heating, including dehydration, sintering and decomposition. With every of these reactions specific kinetics are associated. The study of these reactions kinetics requires a model capable of treating multistep reaction mechanisms. Such models have been developed for several inorganic materials, e.g. for cement ${ }^{20}$, boehmite ${ }^{21}$, and a hydride silica ${ }^{22}$. To study the effects of a thermal treatment on organosilica materials we take a BTESE-derived organosilica as a model system, and compare it 
to purely inorganic, TEOS-derived, silica. The thermal dehydration of silica has been studied extensively in the past. Zhuravlev ${ }^{23}$ has presented an overview of the different steps during the dehydration process for silica gels, including activation energies and reaction orders. In this study, the work of Zhuravlev is expanded by comparing silica with organosilica, thus demonstrating the influence of an organic moiety on the thermal properties of these materials.

Determination of the kinetic triplet for solid-state reactions can be done in various ways. For an overview of these methods, the reader is referred to the excellent overview on kinetics of solidstate reactions that has been drafted based on the recommendations of the ICTAC Kinetics Committee ${ }^{24}$. Kinetic models typically consider the reaction rate a function of only two variables, the temperature $T$ and the conversion $\alpha$ :

$$
\frac{\mathrm{d} \alpha}{\mathrm{d} t}=A \exp \left(\frac{-E_{\alpha}}{R T}\right) f(\alpha)
$$

where $A$ is the pre-exponential constant $\left(\mathrm{min}^{-1}\right), E_{\alpha}$ is the activation energy $\left(\mathrm{J} \mathrm{mol}^{-1}\right), R$ is the gas constant $\left(8.3145 \mathrm{~J} \mathrm{~mol}^{-1} \mathrm{~K}^{-1}\right)$, and $f(\alpha)(-)$ is a reaction model as a function of the conversion. Here, we determine the effective activation energy via a model-free isoconversional method ${ }^{25-27}$, and estimate the corresponding pre-exponential constant via the compensation effect ${ }^{24}$. The obtained parameters are called 'effective' parameters, as they do not necessarily refer to an intrinsic, individual reaction step ${ }^{24}$. For the sake of readability, we refer to the activation energy without the adjective 'effective' from here on. The full reaction model is determined by a multivariate fitting to the experimental data. A complete description of the used models is given in section Error! Reference source not found.. The thus obtained fitting parameters are used to comprehend the thermal treatment process of organosilica materials, and can be used in further studies to predict thermal stability of the hybrid and inorganic materials. 


\section{Experimental}

\section{Materials}

TEOS (for synthesis, Merck), BTESE (pur. 97\%, ABCR Germany), dried ethanol (max 0.01\% $\mathrm{H}_{2} \mathrm{O}$, SeccoSolv ${ }^{\circledR}$, Merck), ethanol (absolute for analysis, EMSURE ${ }^{\circledR}$, Merck) and nitric acid $\left(1 \mathrm{M}\right.$, Titrisol ${ }^{\circledR}$, Merck and $\geq 65 \%(\mathrm{~T})$, Sigma-Aldrich) were used as received. Water was deionized to $18.2 \mathrm{M} \Omega \mathrm{cm}^{-1}$ using a Milli-Q Advantage $\mathrm{A} 10^{\circledR}$ system (Millipore). Oxygen and nitrogen used for TGA-MS were dried with molecular sieve water absorbers. Oxygen was removed from the nitrogen using an oxygen trap (outlet concentration $<1 \mathrm{ppb}_{2}$ ).

\section{Synthesis}

Silica and organosilica sols were prepared via the acid-catalyzed hydrolysis and condensation of TEOS and BTESE, respectively. In a glove box under nitrogen, the silicon precursor was mixed with dried ethanol in a conical flask that was subsequently transferred outside the glove box to an ice bath for cooling. A mixture of $\mathrm{HNO}_{3}$ and water was added drop-wise to the flask in the ice bath, under vigorous stirring. The thus obtained mixture was heated under reflux at $60{ }^{\circ} \mathrm{C}$ for $180 \mathrm{~min}$ (TEOS) or $90 \mathrm{~min}$ (BTESE). After refluxing, the sol was quenched in an ice bath to prevent further reaction. The obtained sols had a molar ratio of 1:3.8:6.4:0.085 (TEOS:ethanol:water:acid) and 1:10.7:6:0.21 (BTESE:ethanol:water:acid).

To obtain powders, the solution was poured into a Petri dish and the ethanol was allowed to evaporate overnight. The obtained flakes were ground to a powder and were placed in a stove at $80{ }^{\circ} \mathrm{C}$ for $60 \mathrm{~min}$. The samples were mixed thoroughly with a spatula after $30 \mathrm{~min}$. The powders were stored at room temperature in glass vials until further use.

\section{TGA-MS}


Thermogravimetric analysis (TGA) was performed on a STA 449 F3 Jupiter ${ }^{\circledR}$ (Netzch), fitted with a TG-only sample holder. Measurements were performed under $70 \mathrm{ml} \mathrm{min}^{-1}$ synthetic air $\left(20 \% \mathrm{O}_{2}\right.$ in $\left.\mathrm{N}_{2}\right)$ or $70 \mathrm{ml} \mathrm{min}{ }^{-1}$ nitrogen, with heating rates $\beta$ of $5,10,15$, and $20{ }^{\circ} \mathrm{C} \mathrm{min}^{-1}$, from room temperature to $1000{ }^{\circ} \mathrm{C}$. Temperature calibration was done using melting standards; measurements were run sample-temperature controlled. Blank corrections with an empty cup were carried out at every different heating rate. Sample masses were determined in-situ, exactly 30 min after starting purge gas flow rate. Using a consistent residence time in the purge gas prior to measurement was found to be a crucial parameter to obtain reproducible TGA-graphs.

Gases evolving during the thermogravimetric analysis were transferred to a mass spectrometer (MS, QMS 403 D Aëolos ${ }^{\circledR}$, Netzch). TGA and MS start times were synchronized, but no correction was applied for the time offset caused by the transfer line time (estimated $<30 \mathrm{sec}$, systematic offset). First, a bar graph scan for $m / z=1-60$ amu was recorded for both silica and organosilica under both nitrogen and air, to determine the evolving $\mathrm{m} / \mathrm{z}$-numbers (data not included here). The detected $m / z$-numbers $(2,12-19,25,26,28-32,40-46)$ were selected and recorded more accurately in multiple-ion-detection mode, with a dwell of $0.5 \mathrm{sec}$ per $\mathrm{m} / \mathrm{z}$-value and a resolution of 50 .

\section{Theoretical calculations}

\section{Analysis of TGA data using advanced isoconversional analysis}

The mass loss as a function of time and temperature was determined using TGA under multiple different heating rate programs. The mass change was converted to conversion $\alpha$ and normalized between 0 and 1. From the data, activation energies were determined following the integral isoconversional method proposed by Vyazovkin and Dollimore ${ }^{25}$, using the modified integral for 
non-linear temperature programs ${ }^{27}$ and variation of the activation energy as a function of conversion ${ }^{26}$. The activation energy is obtained by minimizing the function $\Phi\left(E_{\alpha}\right)$ :

$$
\Phi\left(E_{\alpha}\right)=\sum_{i=1}^{n} \sum_{j \neq i}^{n} \frac{J\left[E_{\alpha}, T_{i}\left(t_{\alpha}\right)\right]}{J\left[E_{\alpha}, T_{j}\left(t_{\alpha}\right)\right]}
$$

where $i=1 . . n$ and $j=1 . . n$ indicate measurements under different heating programs. In this formula, the integral $J$ is given by:

$$
J\left[E_{\alpha}, T_{i}\left(t_{\alpha}\right)\right] \equiv \int_{t_{\alpha-\Delta \alpha}}^{t_{\alpha}} \exp \left[\frac{-E_{\alpha}}{R T_{i}(t)}\right] d t
$$

The integral in equation (3) cannot be solved analytically and was therefore approximated numerically; the minimization of equation (2) was done using MATLAB's fminsearch algorithm 28

\section{Overall data fitting using multivariate analysis of the kinetics}

A multivariate analysis of the kinetics was used to fit the different heating rate curves obtained by TGA with a multistep parallel reaction model represented by ${ }^{29}$ :

$$
\frac{d \alpha_{i}}{d t}=A_{i} \exp ^{-E_{\alpha, i} /(R T(t))} f_{i}\left(a_{i}\right)
$$

Where $i$ denotes the $i$ th reaction with weighing factor $w_{i}$, where the total conversion is given by:

$$
\alpha=\sum_{i}^{n} w_{i} \alpha_{i} \quad \text { and } \quad \sum_{i}^{n} w_{i}=1
$$

To obtain physically realistic values for the kinetic triplet, the risk of overfitting needs to be avoided ${ }^{24}$. To this end, we took the following approach: the number of reaction steps was determined by evaluating the main steps in TGA and MS data; steps with only a small impact on the mass loss were disregarded for the model fit. Initial values for the multistep mechanism were 
taken from the previously determined model-free activation energy, and the corresponding preexponential constant as determined via the compensation effect that is manifested in the method of invariant kinetic parameters ${ }^{24}$. The truncated Sestak-Berggren model $\left(f(\alpha)=\alpha^{m}(1-\alpha)^{n}\right)$ was used to represent the reaction model. MATLAB's build-in ode23-solver was used to integrate equation (4) ${ }^{28}$. Instead of using a single activation energy, the activation energy was modeled as a Weibull-distribution ${ }^{30}$, in which all the activation energies are associated with independent parallel reactions satisfying equation (5). Minimization of the Residual Sum of Squares (RSS) was performed using MATLAB's patternsearch algorithm to detect the global minimum RSS, followed by a run of fminsearch to detect the exact position of the minimum ${ }^{28}$. 


\section{Results and discussion}

\section{Thermogravimetric analysis and mass spectrometry}

Figures 1 and 2 display the mass loss curve and the primary evolved gases during the thermal treatment of silica under nitrogen and air, respectively (an overview of all MS-peaks is given in figures S1 and S2 in the supporting information). The evolution of the mass of silica is similar under inert (nitrogen) and oxidative (air) atmosphere, with the bulk of the mass loss come to pass below $250{ }^{\circ} \mathrm{C}$ and a second mass loss step between 250 and $375{ }^{\circ} \mathrm{C}$. Above $375{ }^{\circ} \mathrm{C}$, further mass loss occurs gradually and individual steps cannot be identified.

Analysis of the evolved gases associates the mass loss steps with the release of specific compounds. The primary mass loss is mainly caused by dehydration. Other, minor compounds that are released are $\mathrm{NO}_{x}$ (from $\mathrm{HNO}_{3}$ catalyst), ethoxy-groups (from reactant and/or solvent), and $m / z=44$, assigned to either $\mathrm{C}_{2} \mathrm{H}_{4} \mathrm{O}$ or $\mathrm{CO}_{2}$ (from reactant and/or solvent). Under an inert atmosphere, $\mathrm{C}_{2} \mathrm{H}_{4} \mathrm{O}$ can be formed by the catalytic conversion of ethanol (or ethoxy-groups) to acetaldehyde and derivatives thereof ${ }^{31,32}$. Under air, further oxidation to $\mathrm{CO}_{2}$ is the most probable explanation for the $m / z=44$ signal. The peak shape of the evolved gases is slightly different under an inert atmosphere than under air, indicating a thermo-oxidative influence under air. However, the impact of this effect is not high enough to cause significant visible differences in the mass loss. At $325^{\circ} \mathrm{C}$, the peak in the mass loss rate is caused by dehydroxylation of

(mainly vicinal) silanol groups ${ }^{23}$. The removal of hydroxyl-groups continues gradually up to $1000{ }^{\circ} \mathrm{C}$. Because of an increase in isolation of the silanol-groups, the rate keeps decreasing. 


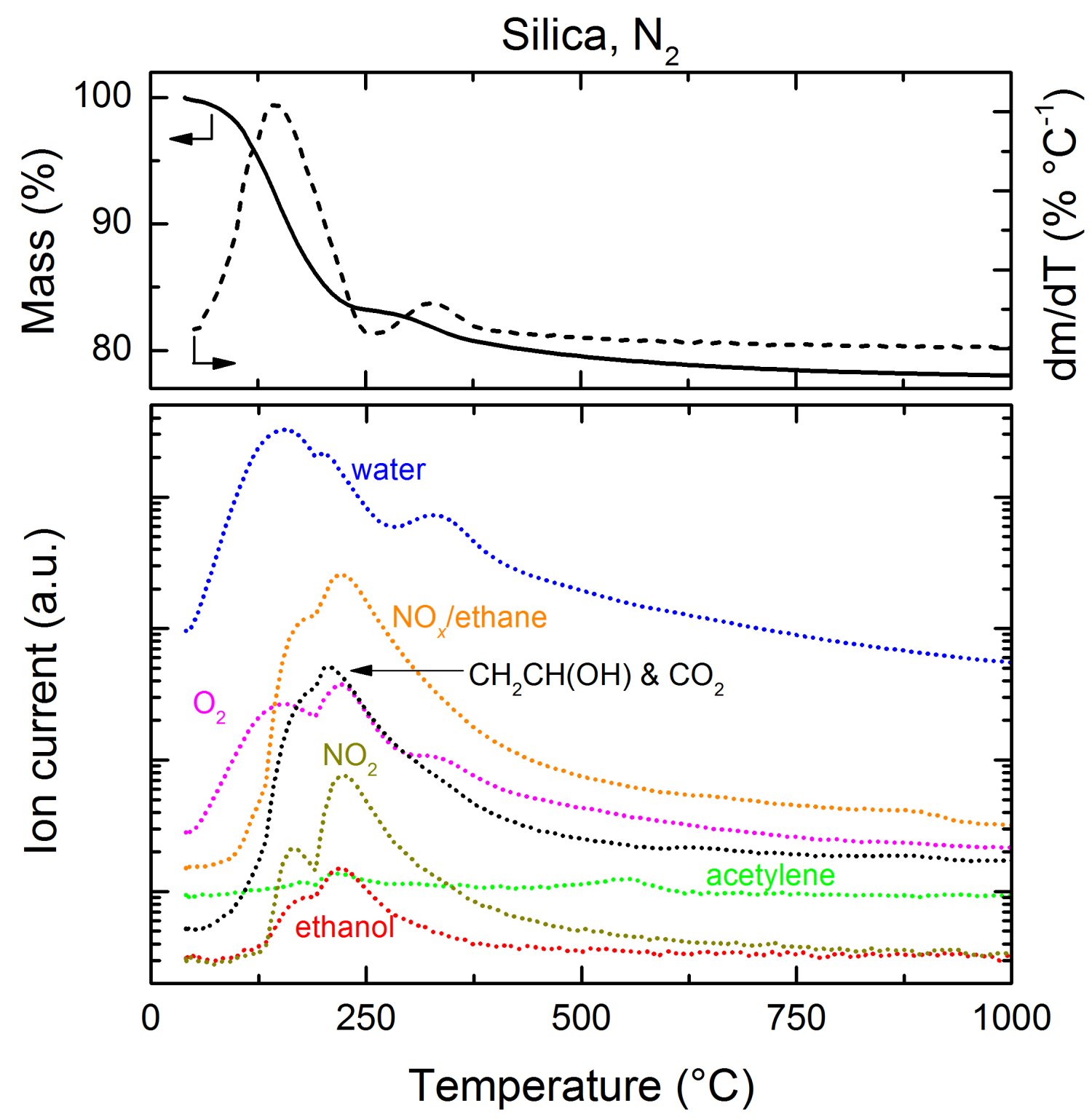

Figure 1: Mass loss and first derivative thereof (top) and evolved gases (bottom) as a function of temperature for silica, heated under nitrogen at $20{ }^{\circ} \mathrm{C} \mathrm{min}^{-1}$. The assigned $\mathrm{m} / z$ signals are: oxygen 16, water 18, acetylene 26, $\mathrm{NO}_{x} 30$, ethanol $31, \mathrm{CH}_{2} \mathrm{CH}(\mathrm{OH})$ and/or $\mathrm{CO}_{2} 44$, and $\mathrm{NO}_{2} 46$. 


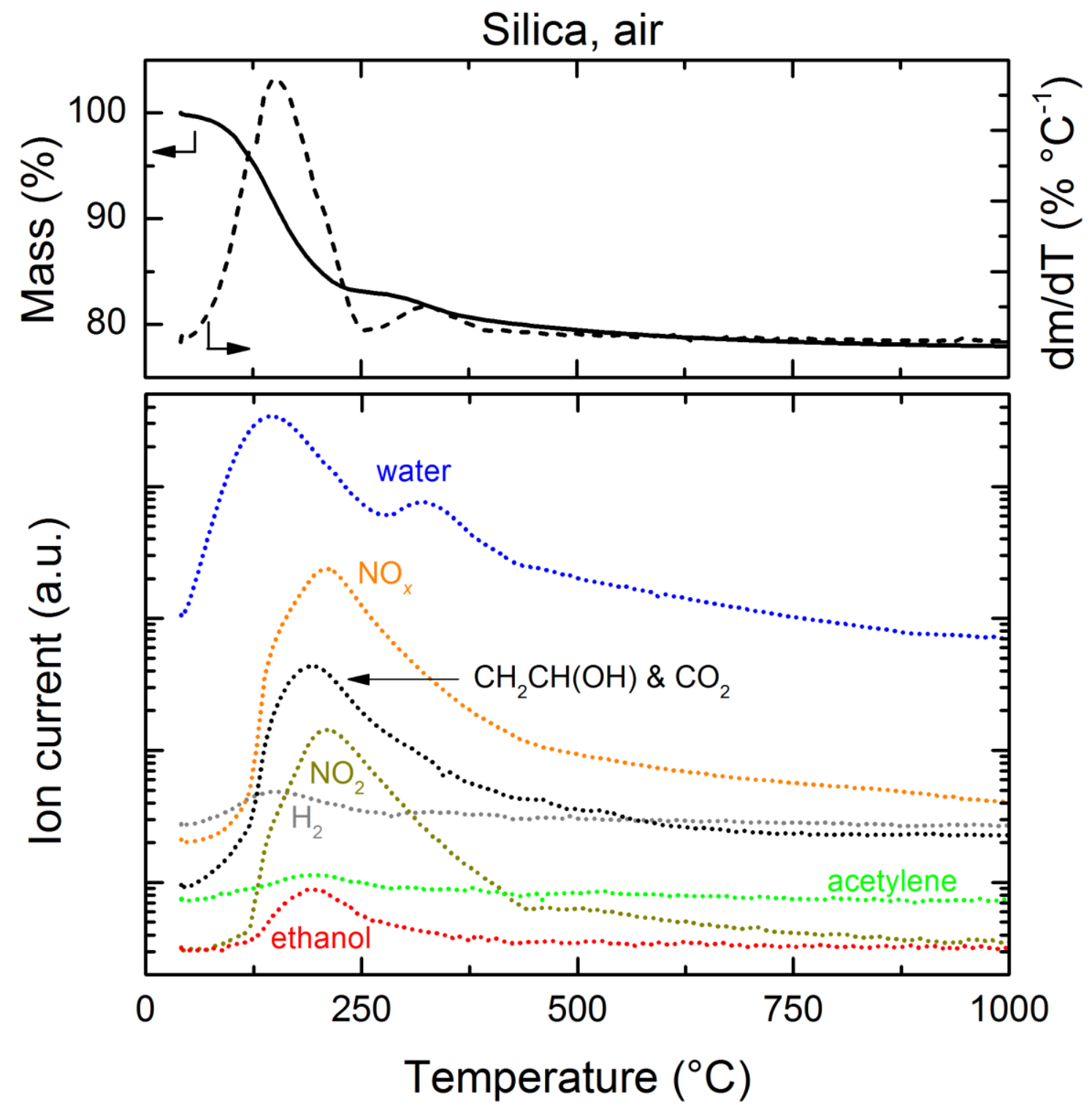

Figure 2: Mass loss and first derivative thereof (top) and evolved gases (bottom) as a function of temperature for silica, heated under air at $20{ }^{\circ} \mathrm{C} \mathrm{min}-1$. The assigned $\mathrm{m} / z$ signals are: hydrogen 2 , water 18, acetylene 26, $\mathrm{NO}_{x} 30$, ethanol 31, $\mathrm{CH}_{2} \mathrm{CH}(\mathrm{OH})$ and/or $\mathrm{CO}_{2} 44$, and $\mathrm{NO}_{2} 46$. 
Figures 3 and 4 display the weight loss curve and the primary evolved gases during the thermal treatment of silica under nitrogen and air, respectively (an overview of all MS-peaks is given in figures S3 and S4 in the supporting information). The differential mass loss curves reveal four dominating mass loss processes. Two of these processes appear similar under both atmospheres: a dehydration step and a sharp decomposition step in which mainly $\mathrm{NO}_{x}$ is released, taking place in the range of $25-250{ }^{\circ} \mathrm{C}$. These results agree with the processes occurring for the thermal treatment of silica, although the extend of the weight loss is different, which is caused by the different Si-precursor: $\mathrm{HNO}_{3}$ :water ratio used in the synthesis of both materials.

Under inert atmosphere, a third mass loss step takes place between 250 and $375{ }^{\circ} \mathrm{C}$. As with silica, this weight loss originates mainly from dehydroxylation of the material. The organic moiety remains intact until $500{ }^{\circ} \mathrm{C}$, where the onset of a release of methane and hydrogen indicate its decomposition. The presence of methane in the evolved gases reveals that the decomposition of the ethyl-bridge takes place through scission of the carbon-carbon bond. The continuous release of hydrogen up to $1000{ }^{\circ} \mathrm{C}$ indicates that hydrogen-containing organic material is still present at these temperatures. The carbonous residue that would result from this dehydrogenation is confirmed by the black appearance of the organosilica after the TGAexperiment.

Under an oxidative atmosphere, the gradual decomposition of the organic moiety initiates at $250{ }^{\circ} \mathrm{C}$. Here, gas release takes place in the form of methane, acetaldehyde, and $\mathrm{C}_{2} \mathrm{H}_{4} \mathrm{O} / \mathrm{CO}_{2}$, indicating that the majority of the decomposition takes place via a thermo-oxidative pathway. The different ratios of the evolved gases with respect to temperature show that the decomposition takes place via a complex multistep mechanism. The apparent drop in the methane release at 625 
${ }^{\circ} \mathrm{C}$ can be assigned to the thermo-oxidation of the methane ${ }^{33}$. The weight loss rate goes down to zero only at $1000^{\circ} \mathrm{C}$.

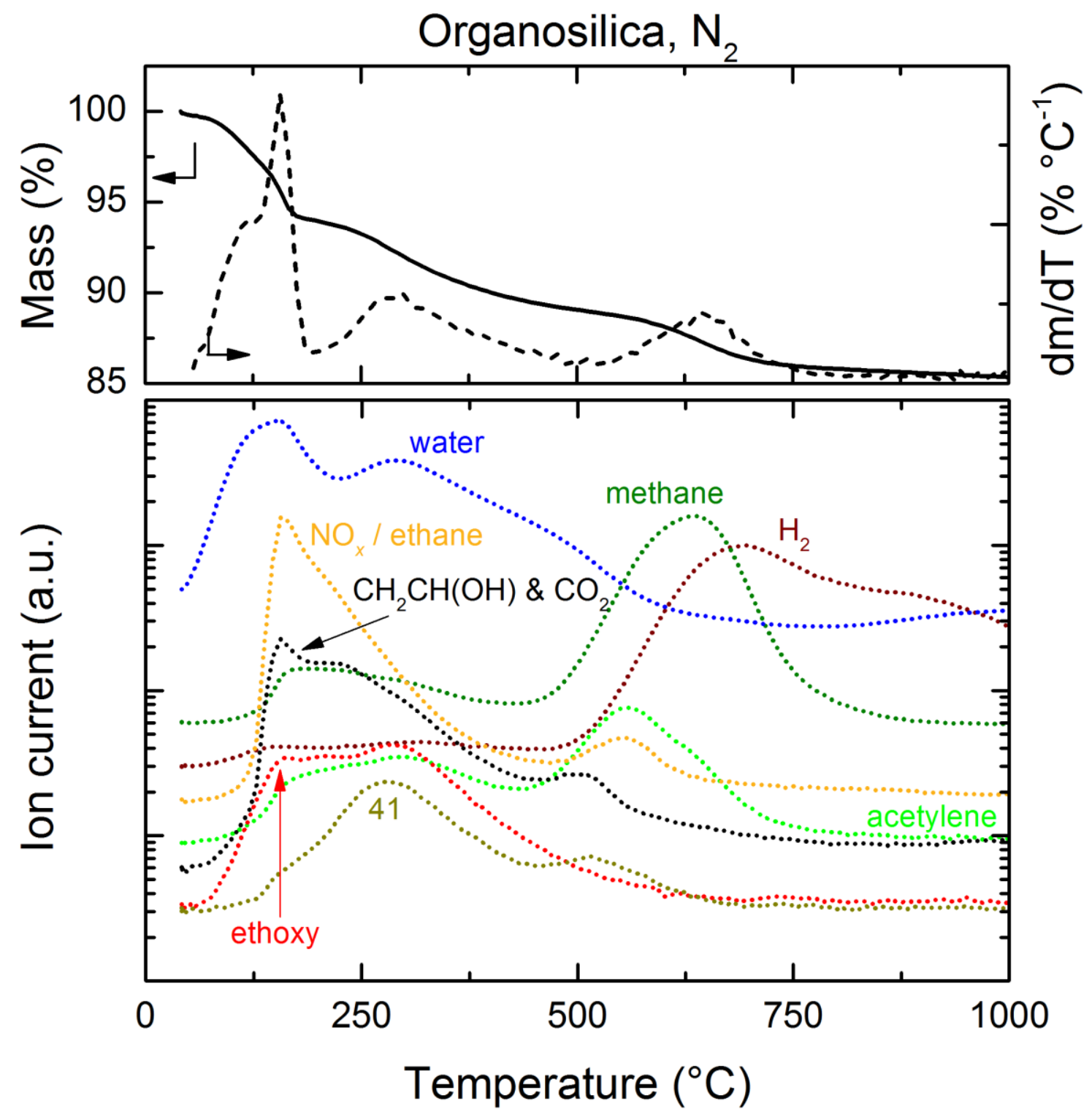

Figure 3: Mass loss and first derivative thereof (top) and evolved gases (bottom) as a function of temperature for organosilica, heated under nitrogen at $20{ }^{\circ} \mathrm{C} \mathrm{min}^{-1}$. The assigned $\mathrm{m} / \mathrm{z}$ signals are: hydrogen 2 , methane 15 , water 18 , acetylene $26, \mathrm{NO}_{x} 30$, unknown $41, \mathrm{CH}_{2} \mathrm{CH}(\mathrm{OH})$ and/or $\mathrm{CO}_{2}$ 44, and ethoxy 45. 


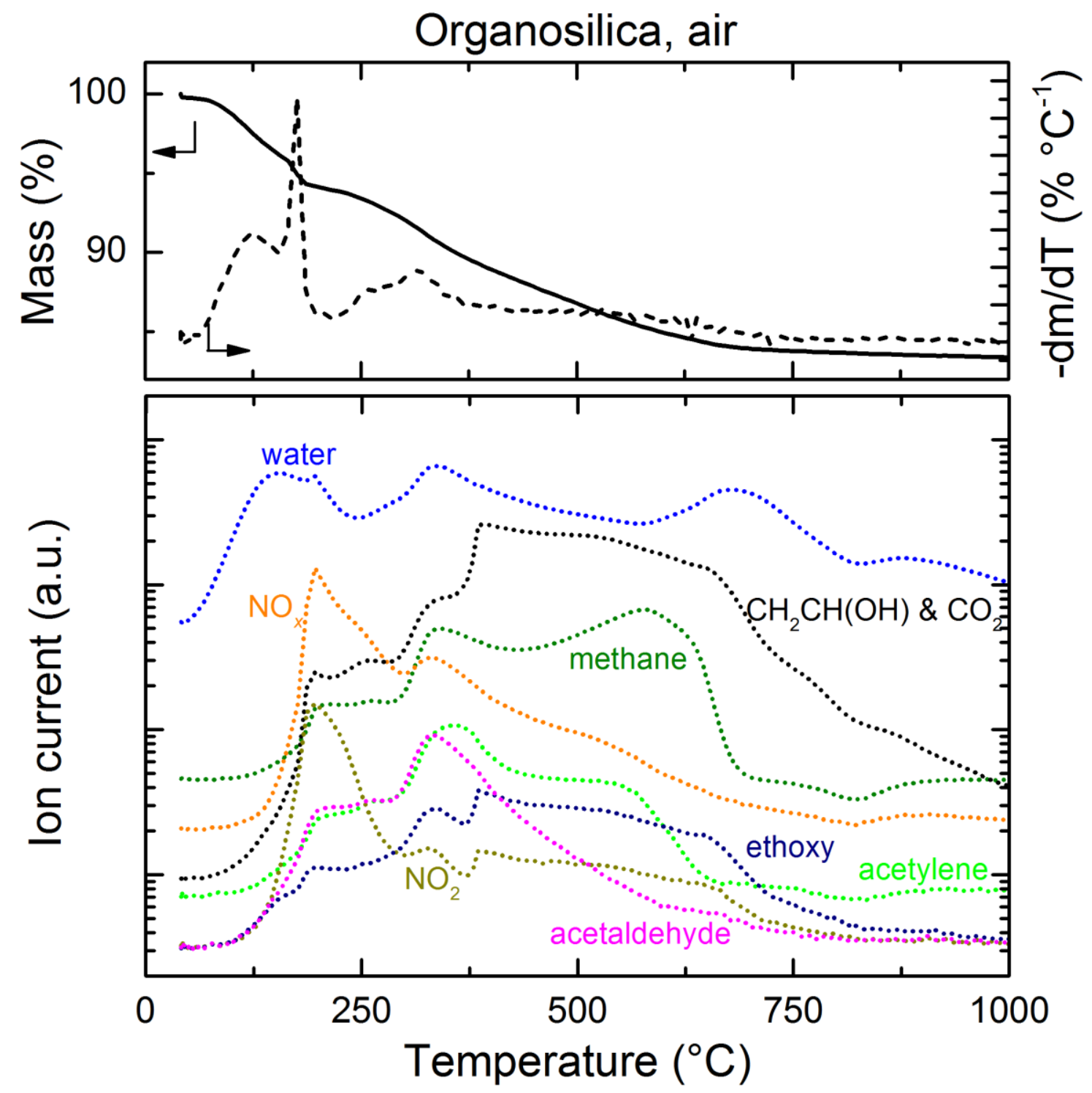

Figure 4: Mass loss and first derivative thereof (top) and evolved gases (bottom) as a function of temperature for organosilica, heated under air at $20{ }^{\circ} \mathrm{C} \mathrm{min}^{-1}$. The assigned $\mathrm{m} / \mathrm{z}$ signals are: methane 15, water 18, acetylene 26, $\mathrm{NO}_{x} 30, \mathrm{CH}_{2} \mathrm{H}_{4} \mathrm{O}$ and/or $\mathrm{CO}_{2} 44$, ethoxy $45, \mathrm{NO}_{2} 46$ 


\section{Determination of activation energies via isoconversional analysis}

Figure 5 shows the apparent activation energy as a function of conversion for silica and organosilica, as obtained from the advanced isoconversional method (2), calculated from the data presented in figures S5-S12. Data is given for treatment under nitrogen (open circles) and air (closed squares). The calculated activation energy is an effective average over the individual reactions that occur at a given degree of conversion. Based on the TGA-MS results (section 0), the major reaction steps can be assigned as shown in 
Table 1.
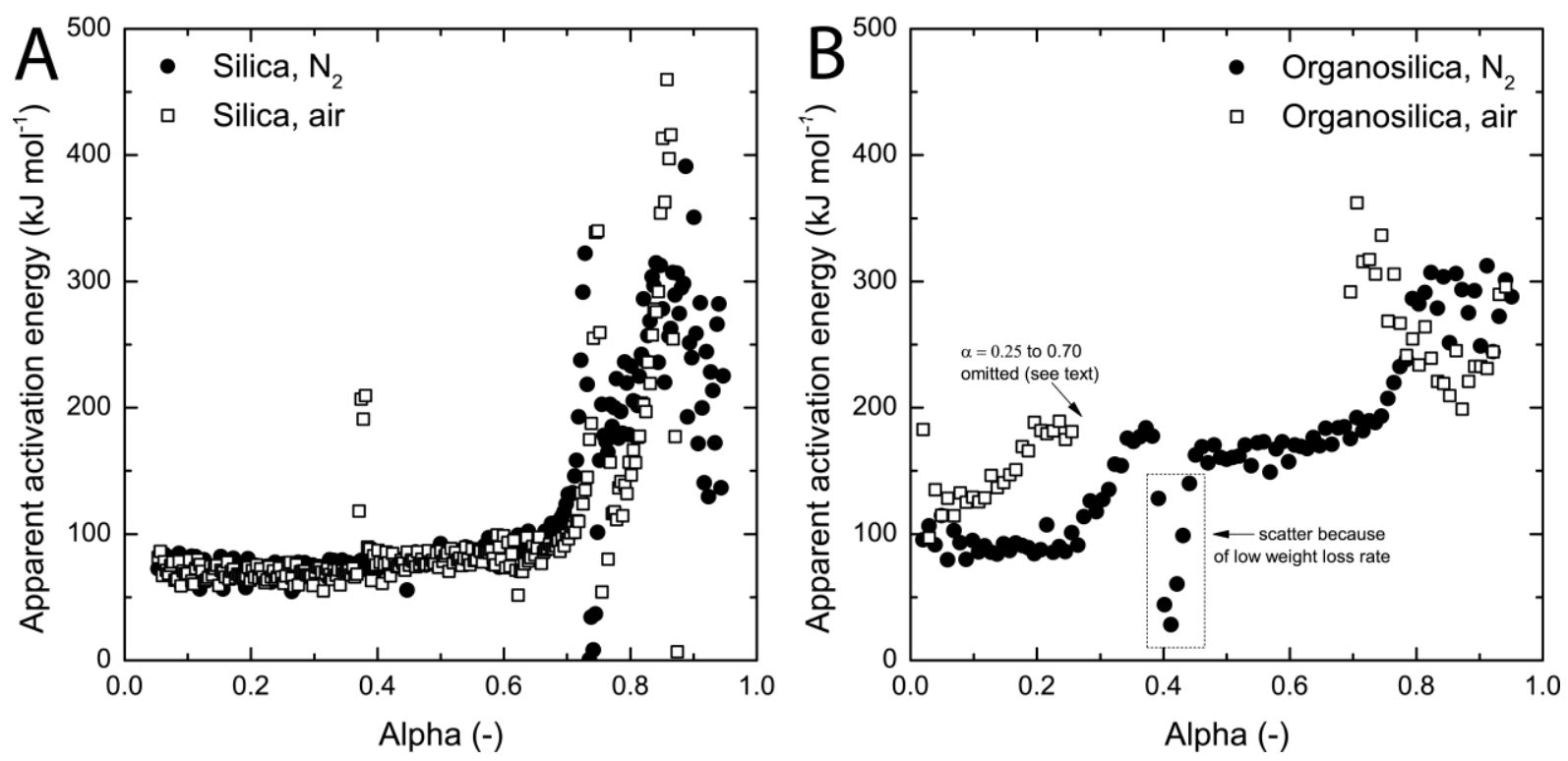

Figure 5: Apparent activation energy determined by the isoconversional analysis of TGA-data for the thermal treatment of silica (a) and organosilica (b) under nitrogen (•) and air ( $\square$ ). Data for organosilica under air is only shown for $\alpha=0-0.25$ and $\alpha=0.7-1$, because of non-physical values for the data in this region (see text). The full version of the graph can be found in figure S13. 
Table 1: Assignment of occurring processes to the mass loss of silica, both under inert atmosphere and air

\begin{tabular}{lll}
\hline Conversion & Process & $\boldsymbol{E}_{\mathbf{a}}\left(\mathbf{k J ~ m o l}^{-\mathbf{1}}\right)$ \\
\hline $0-0.6$ & Dehydration & $76 \pm 3$ \\
$0.6-0.75$ & Dehydration & $76-300$ \\
& $\mathrm{HNO}_{3}$ catalyst decomposition & \\
& Solvent/ethoxy-group & \\
$0.75-0.90$ & Dehydroxylation & $150-300$ \\
$0.90-1$ & Dehydroxylation (thermodynamically limited) & Accurate determination not possible \\
\hline
\end{tabular}

The TGA-MS reveals two major steps in the mass loss. The first is a dehydration step, for which the activation energy for both atmospheres lies within the margins of error. A constant value of the activation energy typically implies that a single reaction dominates the mass loss process ${ }^{24}$. The activation energy reported for this step by Zhuravlev, $25-42 \mathrm{~kJ} \mathrm{~mol}^{-1}{ }^{23}$, is a factor 2-3 lower than the value calculated here. This difference can be caused by the different microstructure (this study: microporous; Zhuravlev's study: mesoporous) if the activation energy is associated with the diffusion process of the water out of the silica network. It has been demonstrated that decreasing pore sizes lead to higher activation energies for diffusion of several gases ${ }^{34}$, and water in particular ${ }^{35}$. Alternatively, this difference may be a result of the use of a single heating rate mass loss curve by Zhuravlev, a method that was later judged to be unreliable for determining activation energies ${ }^{24}$. The first mass loss step is shouldered by the decomposition of the ethoxy-groups and the $\mathrm{HNO}_{3}$ catalyst. In this part, the activation energy is an effective average over the dehydration and decomposition reactions.

The second step is associated with the dehydroxylation of the material. As the amount of vicinal silanol groups decreases, more silanol groups become isolated. However, two silanol 
groups are required for the condensation reaction with the release of water. Because of their isolation, the convergence of silanol groups becomes less frequent, and the activation energy for dehydroxylation rises ${ }^{23}$. With increasing conversion, the mass loss rate decreases, and the relative error in the conversion decreases, leading to scatter in the activation energy data. Above $90 \%$ conversion, the low mass loss rate causes the different heating rate curves to lie close together; because the error in the mass loss becomes similar to the magnitude of the shift in the curves, it is impossible to determine the activation energy in this heating rate range.

Describing the kinetics of dehydration, dehydroxylation and decomposition is more complex for organosilica, since the decompositions of the organic bridging group overlaps (part of) the other processes. Table 2 gives an overview of the specific processes responsible for the mass loss as a function of conversion (see section 0 for the assignments). 
Table 2: Assignment of specific processes to the mass loss conversion of organosilica, both under inert atmosphere and air

\begin{tabular}{|c|c|c|c|c|}
\hline Conversion & Under $\mathrm{N}_{2}$ & $E_{\mathrm{a}}\left(\mathrm{kJ} \mathrm{mol}^{-1}\right)$ & Under air & $E_{\mathrm{a}}\left(\mathrm{kJ} \mathrm{mol}^{-1}\right)$ \\
\hline $0-0.25$ & Dehydration & $91.7 \pm 3.9$ & Dehydration & $130-180$ \\
\hline $0.25-0.45$ & $\begin{array}{l}\text { Dehydration } \\
\text { Catalyst decomposition } \\
\text { Solvent/ethoxy-groups }\end{array}$ & $90-180$ & $\begin{array}{l}\text { Dehydration } \\
\text { Catalyst decomposition } \\
\text { Solvent/ethoxy-groups }\end{array}$ & $*$ \\
\hline $0.45-0.70$ & Dehydroxylation & $160-190$ & $\begin{array}{l}\text { Many reactions, mainly } \\
\text { decomposition or organic } \\
\text { moiety }\end{array}$ & $*$ \\
\hline $0.75-0.95$ & $\begin{array}{l}\text { Decomposition organic } \\
\text { moiety }\end{array}$ & $190-300$ & $\begin{array}{l}\text { Many reactions, mainly } \\
\text { decomposition or organic } \\
\text { moiety }\end{array}$ & $*$ \\
\hline
\end{tabular}

* Accurate determination of the activation energy was not possible for this step

The TGA-MS under $\mathrm{N}_{2}$ reveals four major mass loss steps. The first two steps, responsible for the $40 \%$ conversion, are a dehydration step ( $\alpha=0$ to 0.25 ), and a decomposition step of the solvents/ethoxy-groups and the $\mathrm{HNO}_{3}$ combined with further dehydration ( $\alpha=0.25$ to 0.40$)$. The slightly higher activation energy for the dehydration of the organosilica, as compared to silica, may indicate a difference in the physisorption energy for the two materials, which can be a result from the difference in the pore morphology or and surface chemistry of the materials.

At $\alpha=0.40$, the activation energy shows an apparent drop. This drop is an artifact of the analysis and is physically not realistic: because the mass loss curves are positioned close together, small errors in the mass cause the curves to crossover, which manifests itself in lower or even negative values for the activation energy. The third step is assigned to the dehydroxylation of the organosilica. Although a small increase in the activation energy is observed, this increase is less strong than that of silica. We hypothesize that the organic linking group in the material provides more dynamics for the silanol group, and stabilizes the partial positive charge on the silicon atom 
by electron donation, thus effectively decreasing the energy barrier for dehydroxylation. In the fourth step ( $\alpha=0.75$ to 0.95 ), decomposition of the organic groups take place.

Under air, the thermal treatment of the organosilica forms a complex mixtures of a multitude of decomposition reactions. The only step that can be identified is the dehydration reaction $(\alpha=0$ to $0.25)$. At $\alpha$-values higher than 0.25 , the calculated values for the activation energies are strongly scattered (between -200 and $800 \mathrm{~kJ} \mathrm{~mol}^{-1}$ ) because of a crossover of the mass loss curves (see figure S12). Surprisingly, this crossover is caused by a significant acceleration in the mass loss at higher heating rates. This accelerated mass loss has been observed consistently in triplicate when measurements were repeated (results not shown here). For conversion values higher than 0.70 , the values of the activation energy are physically realistic. However, the unexpected dependence of the mass loss rate on the heating rate indicates that interpretation should be performed with caution. We have therefore limited the determination of kinetic parameters for organosilica to those obtained under inert atmospheres.

\section{Multivariate analysis of the kinetics}

Figure 6 shows the results of the multivariate analysis fit to the data acquired for the thermal treatment of silica under nitrogen. Equation (4) was used for the fitting, with the constraints given in equation (5). The mass ratios of the different steps were determined from the vertical asymptote in the model-free activation energy data (in this case, $w_{1}=0.75$ and $w_{2}=0.15$ ). Both reaction steps were modeled with a Weibull-distributed activation energy for independent parallel reactions. Conversion values larger than 0.9 were omitted, since the magnitude of the shift in the curves was equal to the magnitude of the error. The fit parameters are given in 
Table 3, and the resulting fit is given in Figure 6. 
Table 3: Kinetic parameters for the thermal treatment of silica under nitrogen, fitted with a Weibull-distributed activation energy

\begin{tabular}{l|ll|ll|}
\hline Conversion & $\begin{array}{c}\text { Step 1 }(w=0.75) \\
\text { Nitrogen }\end{array}$ & $\begin{array}{c}\text { Step 2 }(w=0.15) \\
\text { Nitrogen }\end{array}$ & $\begin{array}{c}\text { Step 1 }(w=0.75) \\
\text { Air }\end{array}$ & $\begin{array}{c}\text { Step 2 }(w=0.15) \\
\text { Air }\end{array}$ \\
\hline$A\left(\mathrm{~min}^{-1}\right)$ & $2.65 \cdot 10^{10}$ & $2.56 \cdot 10^{16}$ & $3.03 \cdot 10^{10}$ & $2.47 \cdot 10^{16}$ \\
$E_{\mathrm{a}}$ threshold $\left(\mathrm{kJ} \mathrm{mol}^{-1}\right)$ & 70.6 & 164.1 & 69.2 & 153.4 \\
$\beta(-)$ & 1.52 & 1.39 & 1.98 & 2.08 \\
$\eta\left(\mathrm{kJ} \mathrm{mol}^{-1}\right)$ & 11.4 & 30.1 & 13.9 & 37.3 \\
$E_{a}$ average $\left(\mathrm{kJ} \mathrm{mol}^{-1}\right)$ & 81.0 & 191.5 & 81.5 & 186.4 \\
$m(-)^{*}$ & 0 & 0 & 0 & 0 \\
$n(-)^{*}$ & 1 & 1 & 1 & 1 \\
\hline
\end{tabular}

*Variable not fitted, since it is convoluted with $E_{\mathrm{a}}$. For nitrogen: $\mathrm{RSS}=0.0081, n=9604, p=$ 8 , variance $=8.4 \cdot 10^{-7}$. For air: $\operatorname{RSS}=4.6 \cdot 10^{-7}, n=9604, p=8$, variance $=4.6 \cdot 10^{-7}$.

An identical approach was chosen for the data for BTESE under nitrogen. The mass ratios of the different steps were determined from the vertical asymptote in the model-free activation energy data (in this case, $w_{1}=0.42$ and $w_{2}=0.37$, and $w_{3}=0.15$ ). All reaction steps were modeled with a Weibull-distributed activation energy for independent parallel reactions. Conversion values larger than 0.95 were omitted, since the magnitude of the shift in the curves was equal to the magnitude of the error. The fit parameters are given in 
Table 4. 
Table 4: Kinetic parameters for the thermal treatment of BTESE under nitrogen, fitted with a Weibull-distributed activation energy

\begin{tabular}{|c|c|c|c|}
\hline Conversion & Step $1(w=0.43)$ & Step $2(w=0.37)$ & Step $2(w=0.15)$ \\
\hline$A\left(\min ^{-1}\right)$ & $3.63 \cdot 10^{10}$ & $2.75 \cdot 10^{16}$ & $1 \cdot 10^{18}$ \\
\hline$E_{\mathrm{a}}$ threshold $\left(\mathrm{kJ} \mathrm{mol}^{-1}\right)$ & 68.6 & 156.7 & 302.7 \\
\hline$\beta(-)$ & 2.52 & 1.16 & 0.77 \\
\hline$\eta\left(\mathrm{kJ} \mathrm{mol}^{-1}\right)$ & 14.7 & 48.3 & 27.6 \\
\hline$E_{a}$ average $\left(\mathrm{kJ} \mathrm{mol}^{-1}\right)$ & 81.7 & 202.6 & 335.1 \\
\hline$m(-)^{*}$ & 0 & 0 & 0 \\
\hline$n(-)^{*}$ & 1 & 1 & 1 \\
\hline
\end{tabular}

\footnotetext{
*Variable not fitted, since it is convoluted with $E_{\mathrm{a}} . \mathrm{RSS}=0.0129, n=7206, p=12$, variance $=$ $1.79 \cdot 10^{-6}$
}

For silica, the results of the model fit show good agreement with the data obtained using the model-free isoconversional analysis. The fit matches the data closely, and only seems to deviate slightly for the first and final parts of the dehydration reaction. For the organosilica, the results deviate from those obtained using the model-free methods; especially in the case of the activation energy of the dehydration reaction which is $10 \mathrm{~kJ} \mathrm{~mol}^{-1}$ lower when determined via the multivariate analysis of the kinetics. Here, this may be caused by a correlation of the activation energy with $n$, as a pseudo- $n$-th order reaction is mathematically identical to a gamma distribution or a Weibull distribution (with shape parameter 1 ) in the activation energy ${ }^{30}$. 


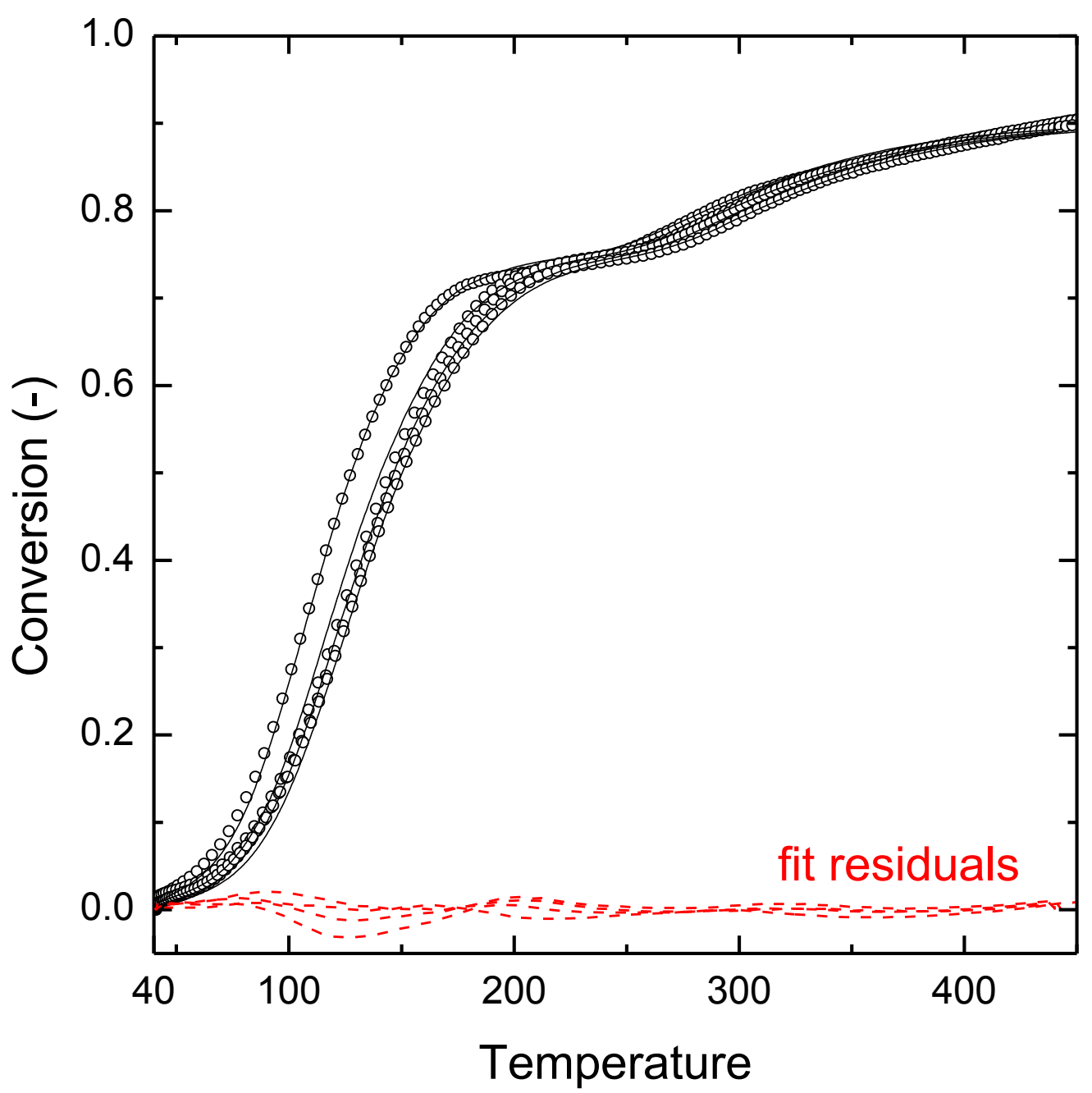

Figure 6: Multivariate fit for the thermal treatment of silica under $\mathrm{N}_{2}$. Symbols depict the experimental data, solid lines represent the fit, and dashed lines show the fit residuals.

\section{Model simulations}

The obtained data can be predicted to determine the conversion of the reaction steps under a chosen heating program. It should be noted that predictions at temperatures, times, and/or heating rates outside of the measurement range have an inherent inaccuracy because of the propagation of errors in the kinetic predictions. The model returns good results within the original measurement range ( $\beta$ between 5 and $20^{\circ} \mathrm{C} \mathrm{min}^{-1}$ ). To further illustrate the model accuracy, data was simulated 
for the thermal treatment of organosilica under $\mathrm{N}_{2}$ under extrapolated conditions: a linear heating rate of $3{ }^{\circ} \mathrm{C} \min ^{-1}$ to $500{ }^{\circ} \mathrm{C}$, followed by a two hour dwell. Figure 7 shows that the experimental data closely follows the model simulation. . Further, the model allows for deconvolution of the data for dehydration, dehydroxylation, and decomposition processes, creating the possibility for fine-tuning of the thermal treatment program, e.g. in order to avoid decomposition of the organic moiety. 


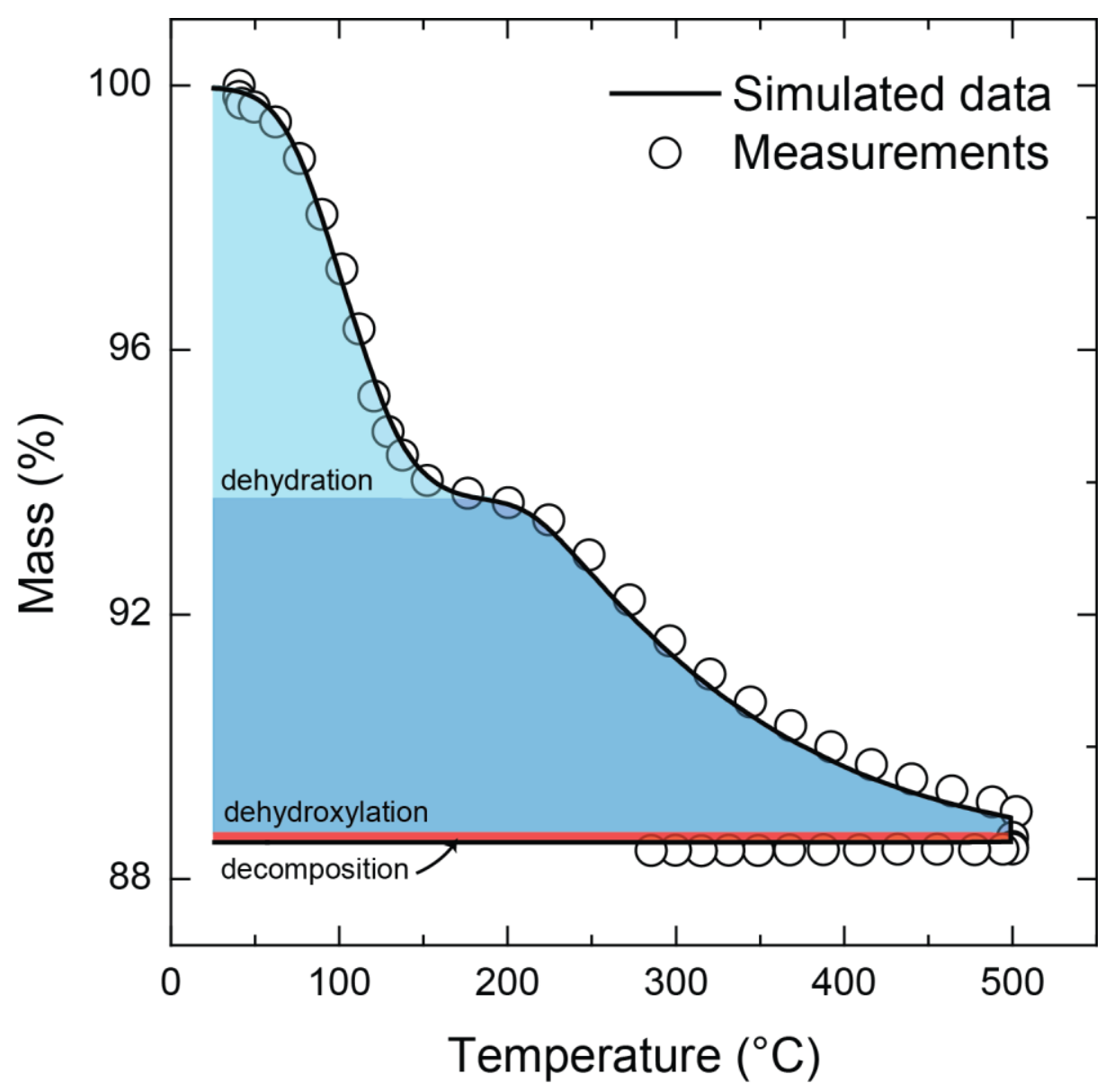

Figure 7: Simulated data (solid line) and measured data $(\circ)$ for the thermal treatment of organosilica under $\mathrm{N}_{2}$ at a heating rate of $3{ }^{\circ} \mathrm{C} \mathrm{min}-1$ including a two hour dwell at $500{ }^{\circ} \mathrm{C}$. The different steps are indicated by the colored area under the graph: dehydration (teal), dehydroxylation (blue), and decomposition (red).

To give guidelines for the thermal processing, Table 5 lists the temperature ranges in which the three identified processes (dehydration, dehydroxylation, and decomposition) occur under three relevant temperature programs: $1{ }^{\circ} \mathrm{C} \min ^{-1}$ and $10{ }^{\circ} \mathrm{C} \min ^{-1}$ as the bound for commonly used heating ranges, and $100{ }^{\circ} \mathrm{C} \mathrm{min}^{-1}$ as an identifier for flash-heating process. 
Table 5: Temperature ranges in which the studied processes take place, for silica and organosilica under nitrogen for three different linear heating rates

\begin{tabular}{|c|c|c|c|}
\hline & \multicolumn{3}{|c|}{$\begin{array}{l}\text { Temperature range for designated process }\left({ }^{\circ} \mathrm{C}\right) \text { for } \\
\text { heating rates of: }\end{array}$} \\
\hline & $\begin{array}{ll}1.1 \quad 1{ }^{\circ} \mathrm{C} \min ^{-1} \\
\\
*\end{array}$ & $10^{\circ} \mathrm{C} \mathrm{min}^{-1}$ & $100^{\circ} \mathrm{C} \mathrm{min}^{-1} *$ \\
\hline \multicolumn{4}{|l|}{ Silica } \\
\hline Dehydration & $33-187$ & $52-228$ & $79-276$ \\
\hline Dehydroxylation & $204-482$ & $230-525$ & $258-573$ \\
\hline Decomposition & - & - & - \\
\hline \multicolumn{4}{|l|}{ Organosilica } \\
\hline Dehydration & $34-159$ & $53-197$ & $80-242$ \\
\hline Dehydroxylation & $185-714$ & $209-770$ & $237-832$ \\
\hline Decomposition & $500-1071$ & $537-1139$ & $578-1216$ \\
\hline
\end{tabular}

Temperature ranges are given as $T_{\text {start }}-T_{\text {end }}$, where $T_{\text {start }}$ is defined as $\alpha=0.01, T_{\text {end }}$ is defined as $\alpha=0.99$. * These heating rates are an extrapolation of the measured data.

\section{Conclusions}

The first step in the thermal treatment of silica-based materials is the removal of physisorbed water from the material. By isoconversional analysis, an effective activation energy of $76 \pm 3 \mathrm{~kJ}$ $\mathrm{mol}^{-1}$ was calculated for the dehydration of silica, irrespective of the atmosphere in which the material is treated, and an effective activation energy of $91.7 \pm 3.9 \mathrm{~kJ} \mathrm{~mol}^{-1}$ was calculated for the dehydration of the organosilica under inert atmosphere; under air atmosphere, it was impossible to determine a single activation energy for the dehydration of the organosilica. The activation energy for dehydration of the organosilica is roughly $20 \%$ higher than that for plain silica; we hypothesize that this is caused by a difference in the binding of the water to the material as a result of the organic bridging group. In both cases, the activation energy is significantly higher 
than the activation energy for evaporating water, $40-43 \mathrm{~kJ} \mathrm{~mol}^{-136}$, suggesting that the water is strongly bound.

The second process that is manifested through the loss of water is the dehydroxylation of the material. For silica, the dehydroxylation reaction has an effective activation energy of $150-300$ $\mathrm{kJ} \mathrm{mol}^{-1}$, and is strongly dependent on the degree of conversion. The strong increase in activation energy is attributed to the increasing spatial separation of the silanol groups, which makes dehydroxylation more difficult. For organosilica, this activation energy is fairly constant at 160$190 \mathrm{~kJ} \mathrm{~mol}^{-1}$; it is hypothesized that this is a result of the enhanced mobility of the organosilica framework that is provided by the organic bridging group.

The third process that is encountered is the decomposition of the organic moiety for organosilica. Under nitrogen, the effective activation energy of this process could be determined to range from $190-300 \mathrm{~kJ} \mathrm{~mol}^{-1}$. Under air, dehydroxylation and decomposition reactions take place simultaneously, rendering it impossible to accurately determine the kinetics of this reaction step.

For organosilica the kinetics of the dehydration, the dehydroxylation, and the decomposition of the organic moiety could be modeled via a multivariate analysis. The developed model allows for a prediction of the conversion of the different reactions as a function of temperature and time. Model simulations for extrapolated heating rates are in excellent agreement with experimentally obtained data. Model simulations for linear heating rates show that full dehydroxylation is always accompanied by a certain extent of decomposition.

Mass loss may not be the sole predictor for the microstructure of a material, as reactions without or with minor mass loss can be decisive in the formation process. Nonetheless, important steps such as dehydration, dehydroxylation, and decomposition of organic moieties can be 
tracked through their mass loss, especially when the evolved gases are analyzed. The determination of reaction kinetics on the basis of TGA/MS-data can form an important addition to the trial-and-error optimization of thermal treatment schemes, and can be used to predict the thermal stability of the synthesized materials.

\section{Author information \\ Corresponding Author \\ * n.e.benes@utwente.nl}

\section{Author Contributions}

The manuscript was written through contributions of all authors. All authors have given approval to the final version of the manuscript.

\section{Funding Sources}

This work is supported by the Helmholtz Alliance MEM-BRAIN, funded by the Initiative and Networking Fund of the Helmholtz Association.

\section{Acknowledgements}

The authors acknowledge the funding of this work by the Helmholtz Alliance MEM-BRAIN. The authors would like to acknowledge the help of Cindy Huiskes with setting up the TGAmeasurements.

\section{Supporting Information}

Supporting Information Available: The supporting information contains all data for the mass spectrometry and thermogravimetric analysis that were used for this article. This material is 
available free of charge via the Internet at http://pubs.acs.org.

\section{References}

(1) Agirre, I.; Arias, P. L.; Castricum, H. L.; Creatore, M.; Ten Elshof, J. E.; Paradis, G. G.; Ngamou, P. H. T.; Van Veen, H. M.; Vente, J. F. Hybrid Organosilica Membranes and Processes: Status and Outlook. Separation and Purification Technology 2014, 121, 2-12.

(2) Wang, J.; Gong, G.; Kanezashi, M.; Yoshioka, T.; Ito, K.; Tsuru, T. Pore-size Tuning of Highly Selective Organic-Inorganic Hybrid Silica Membranes by Solid-phase Posttreatment at Low Temperature. Chemistry Letters 2012, 41, 1663-1665.

(3) Elma, M.; Yacou, C.; Wang, D. K.; Smart, S.; Diniz, J. C. Microporous Silica Based Membranes for Desalination. Water 2012, 629-649.

(4) Chaudhari, M.; Du, J. Reaction Mechanisms of Oxygen Plasma Interaction with Organosilicate Low-k Materials Containing Organic Crosslinking Groups. Journal of Vacuum Science \& Technology A 2012, 30, 61302-61307.

(5) Rathore, J. S.; Interrante, L. V; Dubois, G. Ultra Low-k Films Derived from Hyperbranched Polycarbosilanes (HBPCS). Advanced Functional Materials 2008, 18, 4022-4028.

(6) Loy, D. A.; Shea, K. J. Bridged Polysilsesquioxanes. Highly Porous Hybrid Organicinorganic Materials. Chemical Reviews 1995, 95, 1431-1442.

(7) Manca, M.; Cannavale, A.; De Marco, L.; Aricò, A. S.; Cingolani, R.; Gigli, G. Durable Superhydrophobic and Antireflective Surfaces by Trimethylsilanized Silica Nanoparticlesbased Sol-gel Processing. Langmuir : the ACS journal of surfaces and colloids 2009, 25, 6357-6362.

(8) Wang, J.; Kanezashi, M.; Yoshioka, T.; Tsuru, T. Effect of Calcination Temperature on the PV Dehydration Performance of Alcohol Aqueous Solutions Through BTESE-derived Silica Membranes. Journal of Membrane Science 2012, 415-416, 810-815.

(9) Kanezashi, M.; Shazwani, W. N.; Yoshioka, T.; Tsuru, T. Separation of Propylene/propane Binary Mixtures by Bis(triethoxysilyl) Methane (BTESM)-derived Silica Membranes Fabricated at Different Calcination Temperatures. Journal of Membrane Science 2012, 415-416, 478-485. 
(10) Kreiter, R.; Creatore, M.; Cuperus, F. P.; Vente, J. F.; Herve, T. N. P.; Tchoua Ngamou, P. H. Supported Polysilsesquioxane Membrane and Production Thereof. WO2013066184A1, 2012.

(11) Ngamou, P. H. T.; Overbeek, J. P.; Kreiter, R.; Van Veen, H. M.; Vente, J. F.; Wienk, I. M.; Cuperus, P. F.; Creatore, M. Plasma-deposited Hybrid Silica Membranes with a Controlled Retention of Organic Bridges. Journal of Materials Chemistry A 2013, 1, 5567.

(12) Jang, K.-S.; Kim, H.-J.; Johnson, J. R.; Kim, W.; Koros, W. J.; Jones, C. W.; Nair, S. Modified Mesoporous Silica Gas Separation Membranes on Polymeric Hollow Fibers. Chemistry of Materials 2011, 23, 3025-3028.

(13) Nair, S.; Jang, K.-S.; Jones, C.; Koros, W.; Johnson, J. Mesoporous Silica Membrane on Polymeric Hollow Fibers, 2012.

(14) Wang, J.-S.; Huang, S.-Y. Potential of Low-temperature Post Processing of Silica Gel for High-temperature Stable LED Encapsulant. Journal of Sol-Gel Science and Technology2 12AD.

(15) Schillo, M. C.; Park, I. S.; Chiu, W. V; Verweij, H. Rapid Thermal Processing of Inorganic Membranes. Journal of Membrane Science 2010, 362, 127-133.

(16) Kappert, E. J.; Nijmeijer, A.; Benes, N. E. Expeditious Calcination of Inorganic Membranes by an Instant Temperature Increment. Microporous and Mesoporous Materials 2012, 151, 211-215.

(17) Wang, D. K.; Motuzas, J.; Costa, J. C. D. da; Smart, S. Rapid Thermal Processing of Tubular Cobalt Oxide Silica Membranes. International Journal of Hydrogen Energy 2013, $38,7394-7399$.

(18) Wang, D. K.; Diniz da Costa, J. C.; Smart, S. Development of Rapid Thermal Processing of Tubular Cobalt Oxide Silica Membranes for Gas Separations. Journal of Membrane Science 2014, 456, 192-201.

(19) Van Gestel, T.; Hauler, F.; Bram, M.; Meulenberg, W. A.; Buchkremer, H. P. Synthesis and Characterization of Hydrogen-selective Sol-gel SiO2 Membranes Supported on Ceramic and Stainless Steel Supports. Separation and Purification Technology 2014, 121, $20-29$.

(20) Zhang, Q.; Ye, G. Dehydration Kinetics of Portland Cement Paste at High Temperature. Journal of Thermal Analysis and Calorimetry 2012, 110, 153-158.

(21) Xu, B.; Smith, P. Dehydration Kinetics of Boehmite in the Temperature Range 723-873 K. Thermochimica Acta 2012, 531, 46-53. 
(22) Campostrini, R.; Sicurelli, A.; Ischia, M.; Carturan, G. Pyrolysis Study of a Hydride Solgel Silica. Kinetic Aspects. Journal of Thermal Analysis and Calorimetry 2007, 90, 179184.

(23) Zhuravlev, L. T. The Surface Chemistry of Amorphous Silica. Zhuravlev Model. Colloids and Surfaces A: Physicochemical and Engineering Aspects 2000, 173, 1-38.

(24) Vyazovkin, S.; Burnham, A. K.; Criado, J. M.; Pérez-Maqueda, L. A.; Popescu, C.; Sbirrazzuoli, N. ICTAC Kinetics Committee Recommendations for Performing Kinetic Computations on Thermal Analysis Data. Thermochimica Acta 2011, 520, 1-19.

(25) Vyazovkin, S.; Dollimore, D. Linear and Nonlinear Procedures in Isoconversional Computations of the Activation Energy of Nonisothermal Reactions in Solids. Journal of Chemical Information and Computer Sciences 1996, 36, 42-45.

(26) Vyazovkin, S. Modification of the Integral Isoconversional Method to Account for Variation in the Activation Energy. Journal of Computational Chemistry 2001, 22, 178183.

(27) Vyazovkin, S. Evaluation of Activation Energy of Thermally Stimulated Solid-state Reactions Under Arbitrary Variation of Temperature. Journal of Computational Chemistry 1997, 18, 393-402.

(28) MATLAB and Optimization Toolbox, Release 2012b. In; The MathWorks: Natick, Massachusetts, USA.

(29) Cai, J.; Wu, W.; Liu, R. Isoconversional Kinetic Analysis of Complex Solid-state Processes: Parallel and Successive Reactions. Industrial \& Engineering Chemistry Research 2012, 51, 16157-16161.

(30) Burnham, A. K.; Braun, R. L. Global Kinetic Analysis of Complex Materials. Energy \& Fuels 1999, 13, 1-22.

(31) Matsumura, Y.; Hashimoto, K.; Yoshida, S. Selective Dehydrogenation of Ethanol over Highly Dehydrated Silica. Journal of Catalysis 1989, 117, 135-143.

(32) Hao, Y.; Tao, L.; Zheng, L. Ethanol Dehydrogenation on Silica Pillared Rectorite. Applied Catalysis A: General 1994, 115, 219-228.

(33) Chen, Q.; Hoebink, J. H. B. J.; Marin, G. B. Kinetics of the Oxidative Coupling of Methane at Atmospheric Pressure in the Absence of Catalyst. Industrial \& Engineering Chemistry Research 1991, 30, 2088-2097.

(34) De Lange, R. S. a.; Keizer, K.; Burggraaf, a. J. Analysis and Theory of Gas Transport in Microporous Sol-gel Derived Ceramic Membranes. Journal of Membrane Science 1995, 104, 81-100. 
(35) Li, X.; Li, Z.; Xia, Q.; Xi, H. Effects of Pore Sizes of Porous Silica Gels on Desorption Activation Energy of Water Vapour. Applied Thermal Engineering 2007, 27, 869-876.

(36) Prado, J. R.; Vyazovkin, S. Activation Energies of Water Vaporization from the Bulk and from Laponite, Montmorillonite, and Chitosan Powders. Thermochimica Acta 2011, 524, 197-201. 


\section{Table of Contents graphic}

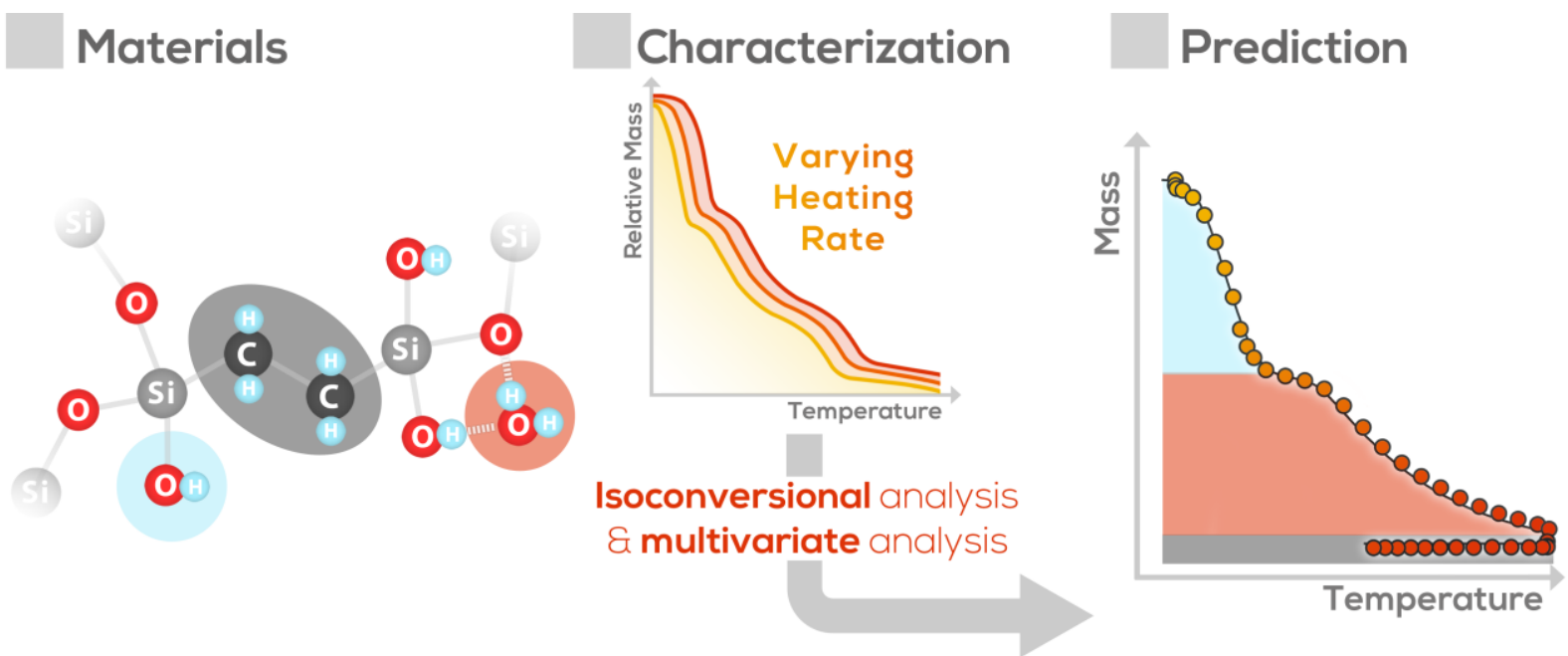

Table of Contents graphics: The materials silica and organosilica have been studied by thermogravimetric analysis under varying heating rates. Analysis with isoconversional analysis and a multivariate analysis of the kinetics result in the values for the kinetic triplet, which allow for prediction of the thermal processing of these materials. 